\title{
Will New Instruments for Endoscopic Ultrasound-Guided Tissue Acquisition Make Us Happy?
}

\author{
Chang-II Kwon \\ Digestive Disease Center, CHA Bundang Medical Center, CHA University, Seongnam, Korea
}

See "Prospective Assessment of the Performance of a New Fine Needle Biopsy Device for EUS-Guided Sampling of Solid Lesions" by Ihab I. El Hajj, Howard Wu, Sarah Reuss, et al., on page 576-583.

Acquisition of cells or tissue using endoscopic ultrasound-guided fine needle aspiration (EUS-FNA) is a basic technique for endoscopists. Accurate identification of target lesion and location, appropriate penetration technique, and collaboration with the pathologist are all critical to achieving successful outcomes. ${ }^{1}$ Although direct tissue examination by a pathologist in the endoscopy room is the ideal method of processing tissue samples (Rapid On-Site Evaluation, ROSE), this is not practical in most hospitals. For this reason, it is vital that tissue be obtained properly as the endoscopist must decide whether to complete the EUS-FNA with the sample obtained during the examination. In this regard, several competing companies have introduced accessories that vary the shape of the needle to simplify decision-making by the endoscopist. This editorial considers the ability of these new products to overcome existing limitations and improve the general attitude of the endoscopist in the workplace.

Received: September 21, 2018 Revised: October 23, 2018

Accepted: October 25, 2018

Correspondence: Chang-Il Kwon

Digestive Disease Center, CHA Bundang Medical Center, CHA University, 59 Yatap-ro, Bundang-gu, Seongnam 13496, Korea

Tel: +82-31-780-5641, Fax: +82-31-780-5219, E-mail: endoscopy@cha.ac.kr ORCID: https://orcid.org/0000-0003-3621-9023

(c) This is an Open Access article distributed under the terms of the Creative Commons Attribution Non-Commercial License (http://creativecommons.org/ licenses/by-nc/3.0) which permits unrestricted non-commercial use, distribution, and reproduction in any medium, provided the original work is properly cited.

\section{Acquire $^{\mathrm{TM}}$ endoscopic ultrasound fine needle biopsy device}

The cutting edge tip of the Acquire ${ }^{\mathrm{TM}}$ needle (Boston Scientific Co., Natick, MA, USA) is symmetrically structured on three sides, with the shape designed to minimize resistance to accurate target and needle penetration (Fig. 1). The geometric needle structure, incorporating small and large inclination angles, is shaped like a crown, and is designed for deeper insertion to support core biopsies. The first retrospective study of this Franseen tip needle reported that both diagnostic adequacy and accuracy was $>95 \%$. The first prospective randomized trial by the same researchers reported no difference in yielding histological tissue compared with the fork-tip

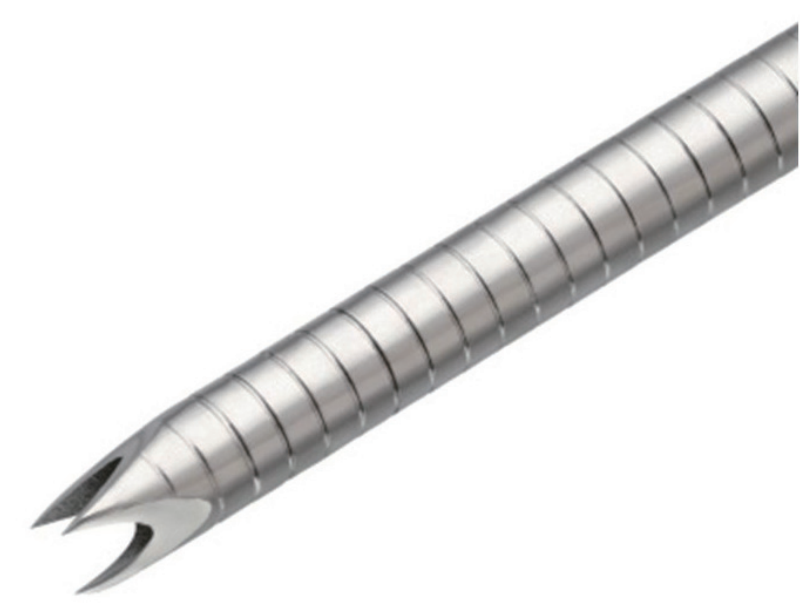

Fig. 1. Tip of the Acquire ${ }^{T M}$ endoscopic ultrasound biopsy device (Boston Scientific Co., Natick, MA, USA). 
needle. ${ }^{3}$ However, another study, although not a prospective randomized controlled trial, reported that the fork-tip needle was superior, especially when diagnosing a pancreatic mass. ${ }^{4}$ In a realistic situation where ROSE is not available, this discrepancy could be larger. How many passes are needed to get the proper tissue without ROSE, which might result in more complications?

In a recent study in Clinical Endoscopy, El Hajj et al. ${ }^{6}$ reported on a randomized trial comparing the overall diagnostic performance between this $22-\mathrm{G}$ Franseen needle and the historical FNA needle in sampling solid tumors. In addition, the study evaluated the number of needle passes and the cytological quality of smears required to enable immediate ROSE. They demonstrated the superiority of the Franseen needle through cytological and histological scoring systems (2.32 vs. $2.02, p=0.046)$ and demonstrated that fewer passes are needed ( 2.88 vs. $3.82, p<0.001$ ). There were no serious complications as a result of the procedure. The target tissues obtained using the core biopsy needles were obtained mainly as fragments. The authors compared these using smears and cell block technique instead of histological examination to determine the feasibility
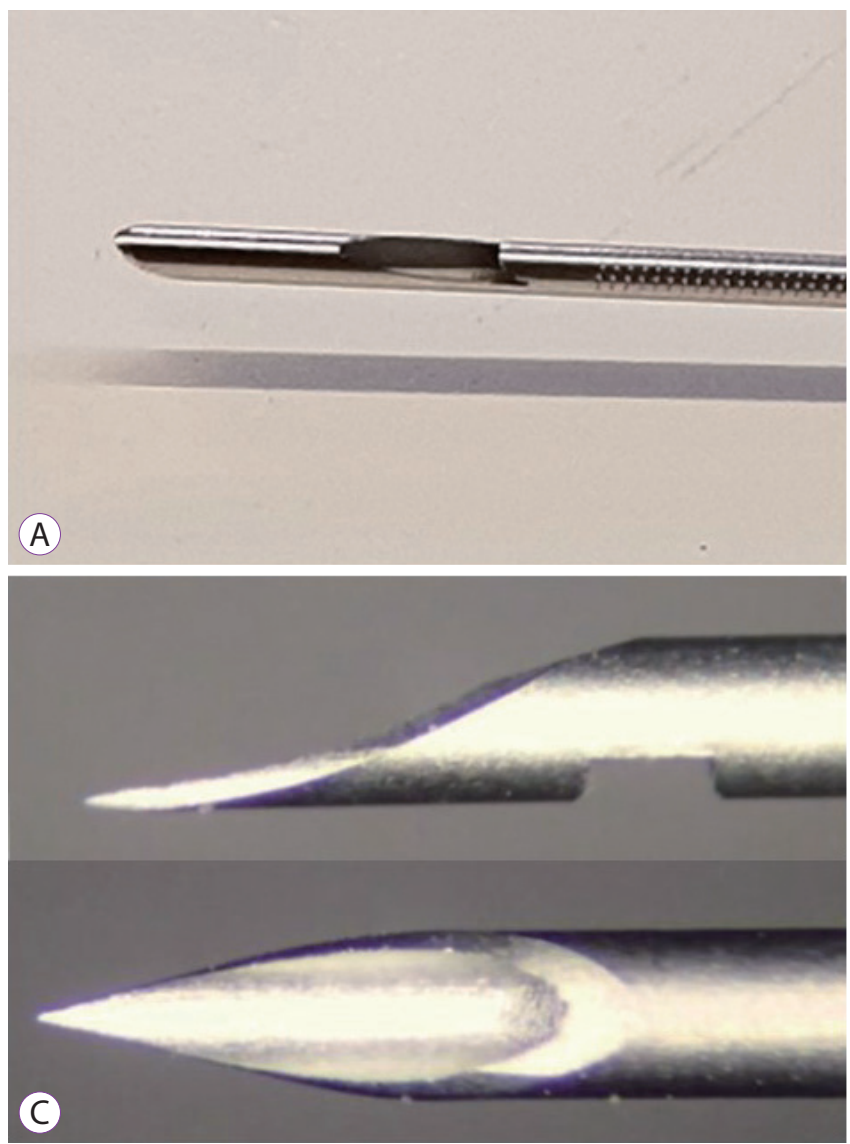

of ROSE. In addition, they showed various histologic samples and explained in detail how they were assessed.

\section{EchoTip ProCore ${ }^{\circledR}$ HD ultrasound biopsy needle (20-G)}

The newly released EchoTip ProCore ${ }^{\circledR}$ (Cook Medical, Bloomington, IN, USA) has been designed to complement the pros and cons of the existing ProCore ${ }^{\circledR}$ needle (Fig. 2A). The $20-\mathrm{G}$ needle was designed to match the size of the tissue with the flexibility of the needle. To enable core sampling, the direction of the oblique hole of the shaft was made opposite to that of the previous needle. The improved flexibility has made it easier to insert the needle and obtain a core biopsy, even in difficult anatomic locations when compared with the previous needle. Although a meta-analysis study of the ProCore ${ }^{\mathbb{B}}$ needle showed no difference from conventional FNA needles in terms of diagnostic adequacy, diagnostic accuracy, or core biopsy acquisition rate, the number of needle passes required for diagnosis was significantly lower when using the ProCore ${ }^{\circledR}$ needle. ${ }^{7}$ Recent studies using the new $20-\mathrm{G}$ core biopsy needles indicated improved results. ${ }^{8-10}$

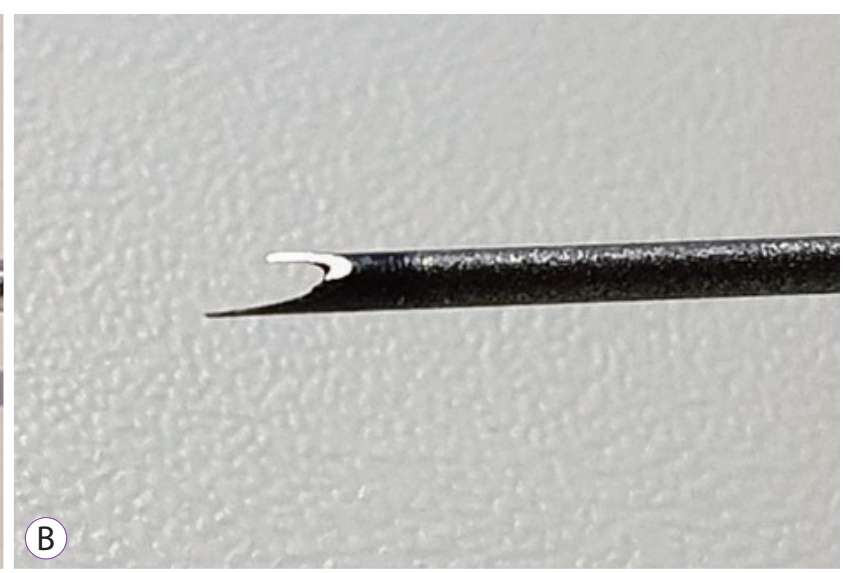

(D)

Fig. 2. (A) EchoTip ProCore ${ }^{\circledR}$ HD endoscopic ultrasound biopsy device (Cook Medical, Bloomington, IN, USA). (B) Tip of the Sharkcore ${ }^{\mathrm{TM}}$ endoscopic ultrasound biopsy device (Medtronic Inc., Minneapolis, MN, USA). (C) EZ Shot 3 Plus endoscopic ultrasound needle (Olympus, Tokyo, Japan). (D) Moray ${ }^{\text {TM }}$ Micro Forceps (US endoscopy, Mentor, $\mathrm{OH}$, USA). 


\section{SharkCore ${ }^{\mathrm{TM}}$ needle}

The six distal cutting edges of SharkCore ${ }^{\mathrm{TM}}$ needle (Medtronic Inc., Minneapolis, MN, USA) were designed to be precisely inserted into the center of the tissue without disturbing the tissue architecture (Fig. 2B). The name of this needle is inspired by the shape of a shark's mouth. This fork-tip needle enables core sampling, with minimized tissue stacking and fracturing (even for severely fibrotic lesions), and enhanced diagnostic yield. Results of initial studies reported a tissue acquisition rate of more than $90 \%$ and a diagnostic accuracy of $83 \%-93 \%{ }^{11-14}$

\section{EZ Shot 3 Plus}

In order to improve accessibility, EZ Shot 3 Plus (Olympus, Tokyo, Japan) was changed from conventional stainless steel to Nitinol, and the covering material was changed from plastic to a coil (Fig. 2C). These changes increased the tissue acquisition rate in the head of the pancreas, which due to the required angle, is deemed to be the most difficult location to obtain tissue. Furthermore, these changes prevented the Nitinol needle from deflecting, despite multiple insertions. In addition, due to the product being released at a lower price, it can be considered competitive with relatively expensive products designed by other companies.

\section{Moray ${ }^{\mathrm{TM}}$ Micro Forceps}

The Moray ${ }^{\mathrm{TM}}$ Micro Forceps (US endoscopy, Mentor, OH, USA) are designed to acquire the inner tissue of cystic lesions as opposed to fluid analysis using EUS-FNA (through-theneedle biopsy forceps) (Fig. 2D). These biopsy forceps can be inserted through all 19-G EUS-FNA needles of other companies, and positive results have been reported. ${ }^{15-17}$

There is no doubt that the newer needles currently in use, and those that are continually being developed, will yield better results. In considering these needles for practice it is vital to examine not only the shortened procedure time and accuracy of the test, but also how conveniently and easily the exam can be performed (especially at the head of the pancreas), as well as to objectively evaluate whether the test can be completed safely. It is hoped that further studies will involve research into these areas.

Conflicts of Interest

The author has no financial conflicts of interest.

\section{REFERENCES}

1. Bhatia V, Varadarajulu S. Endoscopic ultrasonography-guided tissue acquisition: how to achieve excellence. Dig Endosc 2017;29:417-430.

2. Bang JY, Hebert-Magee S, Hasan MK, Navaneethan U, Hawes R, Varadarajulu S. Endoscopic ultrasonography-guided biopsy using a Franseen needle design: initial assessment. Dig Endosc 2017;29:338-346.

3. Bang JY, Hebert-Magee S, Navaneethan U, Hasan MK, Hawes R, Varadarajulu S. Randomized trial comparing the Franseen and fork-tip needles for EUS-guided fine-needle biopsy sampling of solid pancreatic mass lesions. Gastrointest Endosc 2018;87:1432-1438.

4. Abdelfatah MM, Grimm IS, Gangarosa LM, Baron TH. Cohort study comparing the diagnostic yields of 2 different EUS fine-needle biopsy needles. Gastrointest Endosc 2018;87:495-500.

5. El Hajj II, Al-Haddad M. EUS-FNA giving way to fine-needle biopsy: is it time to retire your old trusted needles? Gastrointest Endosc 2018;87:1439-1442.

6. El Hajj II, Wu H, Reuss S, et al. Prospective assessment of the performance of a new fine needle biopsy device for EUS-guided sampling of solid lesions. Clin Endosc 2018;51:576-583.

7. Bang JY, Hawes R, Varadarajulu S. A meta-analysis comparing ProCore and standard fine-needle aspiration needles for endoscopic ultrasound-guided tissue acquisition. Endoscopy 2016;48:339-349.

8. Chong CCN, Teoh AYB, Tang RSY, Chan AWH, Ng EKW, Lai PBS. EUS-FNA using $22 \mathrm{G}$ nitinol or ProCore needles without on-site cytopathology. Endosc Ultrasound 2018;7:56-60.

9. Antonini F, Delconte G, Fuccio L, et al. EUS-guided tissue sampling with a 20-gauge core biopsy needle for the characterization of gastrointestinal subepithelial lesions: a multicenter study. Endosc Ultrasound 2018 May 17 [Epub]. https://doi.org/10.4103/eus.eus_1_18.

10. Barresi L, Tarantino I, Ligresti D, Curcio G, Traina M. EUS fine-needle aspiration and biopsy with a new 20-gauge needle with side port in a pancreatic cystic lesion. Gastrointest Endosc 2016;84:860-861.

11. DiMaio CJ, Kolb JM, Benias PC, et al. Initial experience with a novel EUS-guided core biopsy needle (SharkCore): results of a large North American multicenter study. Endosc Int Open 2016;4:E974-E979.

12. El Chafic AH, Loren D, Siddiqui A, Mounzer R, Cosgrove N, Kowalski T. Comparison of FNA and fine-needle biopsy for EUS-guided sampling of suspected GI stromal tumors. Gastrointest Endosc 2017;86:510-515.

13. Ishikawa T, Mohamed R, Heitman SJ, et al. Diagnostic yield of small histological cores obtained with a new EUS-guided fine needle biopsy system. Surg Endosc 2017;31:5143-5149.

14. Kandel P, Tranesh G, Nassar A, et al. EUS-guided fine needle biopsy sampling using a novel fork-tip needle: a case-control study. Gastrointest Endosc 2016;84:1034-1039.

15. Nakai Y, Isayama H, Chang KJ, et al. A pilot study of EUS-guided through-the-needle forceps biopsy (with video). Gastrointest Endosc 2016;84:158-162.

16. Kovacevic B, Karstensen JG, Havre RF, et al. Initial experience with EUS-guided microbiopsy forceps in diagnosing pancreatic cystic lesions: a multicenter feasibility study (with video). Endosc Ultrasound 2018 Aug 27 [Epub]. https://doi.org/10.4103/eus.eus_16_18.

17. Barresi L, Crinò SF, Fabbri C, et al. Endoscopic ultrasound-throughthe-needle biopsy in pancreatic cystic lesions: a multicenter study. Dig Endosc 2018;30:760-770. 